
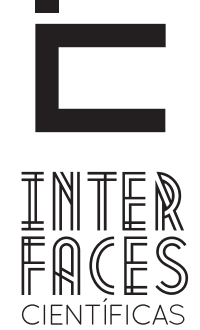

DIREITO

\title{
BREVE ANÁLISE SOBRE O FENÔMENO DA JUDICIALIZAÇÃO DA POLÍTICA E A SUA REPERCUSSÃO SOBRE AS RELAÇ̃̃ES EXTERNAS
}

Maria Anita Araruna Corrêa'

\section{RESUMO}

0 presente estudo propõe-se a delimitar o conceito de judicialização da política, detalhando as principais características de cada elemento que o compõe. Porém, o objeto de análise volta-se para as repercussões deste fenômeno nas relações externas. Busca-se traçar breves considerações sobre o atual processo decisório brasileiro, detalhando o devido processo legal. Aponta-se, por último, algumas possíveis consequências que o teor de determinados pronunciamentos judiciais podem acarretar na órbita internacional.

\section{PALAVRAS-CHAVE}

Judicialização da política. Decisões judiciais. Política externa.

\section{ABSTRACT}

The present study proposes to define the concept of judicialization of politics, detailing the main characteristics of each element that composes it. However, the purpose of analysis turns to the repercussions of this phenomenon on the external relations. It seeks to outline brief considerations about the current Brazilian decision process, detailing the due legal process. Finally, it points out some possible consequences that the content of certain judicial pronouncements can lead on an international orbit.

\section{KEYWORDS}

Judicialization of Politics. Judicial Decision. Foreign Policy. 


\section{RESUMEN}

El presente estudio se propone a delimitar el concepto de judicialización de la política, detallando las principales características de cada elemento que lo compone. Pero, el objeto de análisis se vuelve hacia las repercusiones de este fenómeno en las relaciones externas. Se busca trazar breves consideraciones sobre el actual proceso decisorio brasileño, detallando el debido proceso legal. Se apunta, por último, algu-

\section{INTRODUÇÃO}

Atualmente, tem-se assistido uma postura ativa por parte do Supremo Tribunal Federal, sua atuação tem se destacado nas manchetes de jornais, capas de revistas, de forma que se mantém sempre presente no cotidiano da população. Cada decisão tomada pela corte em questão tem sido objeto de análise por parte dos estudiosos. A repercussão é cada vez maior. Desse modo, verifica-se que o Tribunal de órgão de cúpula do Poder Judiciário, que, a princípio, deveria atuar apenas no exercício da prestação jurisdicional, passa a ser o centro do atual cenário econômico, político e social.

A ampliação da competência do judiciário, notadamente a legislação sobre controle de constitucionalidade, promulgada no final da década de 90 , foi responsável por ampliar a competência da função judiciária, bem como por permitir uma nova atuação da Corte Suprema no cenário nacional. Desse modo, observa-se que a atuação deixa de ser a pura prestação jurisdicional, assim, gradativamente, tendo-se início o fenômeno da judicialização da política.

Segundo Peixinho (2008), a judicialização da política tem por significado a intervenção decisória do Poder Judiciário com capacidade de afetar a conjuntura política nas democracias contemporâneas. A consequência imediata dessa intervenção é a ampliação do poder judicial em matérias que seriam reservadas nas posibles consecuencias que el contenido de determinados pronunciamientos judiciales puede acarrear en la órbita internacional.

\section{PALABRAS CLAVE}

Judicialización de la Política. Decisiones judiciales. Política Externa. às competências dos Poderes Executivo e Legislativo com inspiração na teoria do checks and balances (verificar e equilibrar).

Assim, o estudo do fenômeno denominado "judicialização da política” terá por escopo, em síntese, analisar o papel político dos juízes, notadamente em virtude da expansão do poder dos tribunais, conforme mencionado nas linhas anteriores, além de verificar como tem ocorrido a interação entre os poderes, uma vez que um dos poderes teve suas atribuições expandidas.

Como consequência das mudanças explanadas, o Brasil passa a ter profundas transformações, notadamente no que concerne ao papel do judiciário. Vive-se a fase de uma redefinição das atribuições desta função, posto que com a expansão de demandas, este ainda não logrou êxito em demonstrar qual é o seu verdadeiro papel no atual cenário social, atuando, por vezes, em temas que, em um primeiro momento, deveriam ser do poder legislativo.

Considerando que o fenômeno da globalização ocasionou transformações sociais, por permitir maior interação entre diversas pessoas e diferentes informações, observa-se, com grande velocidade, o surgimento de demandas novas, fatos sociais ainda não abordados pela função legiferante. 
Tendo em vista, que tais anseios sociais não podem aguardar por uma resposta legislativa, o indivíduo busca a tutela jurisdicional, com o escopo de resguardar seu direito, inobstante a ausência de norma. Assim, por não ter como se eximir de fornecer resposta a tais indagações, atua em determinadas esferas que não foram objeto de atuação da função legislativa.

\section{BREVE ANÁLISE DA EVOLUÇÃO HISTÓRICA DA TEORIA DOS FREIOS E CONTRAPESOS}

Sabe-se que a concepção histórica e o desenvolvimento da ideia de estado modificaram-se ao logo das gerações. Segundo Azambuja (2005), nas civilizações orientais, não havia uma concepção definida sobre o que era o estado, notadamente em virtude da instabilidade destes estados. No Estado Hebreu, por exemplo, houve uma teocracia, restrita, tanto pelos preceitos da lei divina, bem como pela fiscalização que as 12 tribos exerciam.

Nas palavras de Coulanges (2006, p. 289):

Em todas as nações antigas o direito sujeitara-se à religião e dela recebera todas as suas normas. Entre os persas e hindus, entre os judeus, entre os gregos, os itálicos e os gauleses, a lei estivera contida nos livros sagrados ou na tradição religiosa.

Na sociedade grega, não, havia uma separação entre a esfera civil e religiosa. 0 estado confundia-se com a igreja, com a religião, caminhavam entrelaçados, qualquer manifestação cívica adquiria também caráter religioso. Assevera Azambuja (2005, p. 165): “O Estado se imiscui em tudo; a Moral e o Direito não the limitam o poder. Ele dispõe do corpo e mesmo da alma dos cidadãos; obriga a aceitação de cargos, como se fosse serviço militar".

Destaca-se que foi em um ambiente como este que Aristóteles desenvolveu as primeiras ideias sobre a necessidade de separação das funções estatais. Se-
Em decorrência da extensão do trabalho, o presente artigo terá por escopo analisar a repercussão da judicialização da política no tocante às relações internacionais, partindo-se do pressuposto que determinadas decisões judiciais tem repercussão externa, por tratarem de relações entre estados internacionais, principalmente sobre o modo do Brasil se relacionar com estes.

gundo Liberato (2010), na concepção de Aristóteles, uma constituição "bem ordenada" deve conter três funções, a primeira relacionada à deliberação de assuntos públicos, segunda, e, por último, relacionada às funções públicas. Com efeito, sustenta Bonavides (2000, p. 156):

\begin{abstract}
O princípio da separação de poderes, de tanta influência sobre o moderno estado de direito, embora tenha tido sua sistematização na obra de Montesquieu, que o empregou claramente como técnica de salvaguarda da liberdade, conheceu todavia precursores, já na antiguidade, já na idade Média e tempos modernos. Distinguira Aristóteles a assembléia-geral, o corpo de magistrados e o corpo judiciário.
\end{abstract}

Segundo Tabosa (1999), Roma Antiga, berço da civilização moderna, demonstrou preocupação em diferenciar as diversas funções do governo, e confiá-la a diferentes órgãos, pois apresentou forte tendência para uma centralização política. Destaca ainda que os cidadãos possuíam direito a um julgamento realizado por um órgão específico, o que denota a ideia da existência de um outro poder, ainda que dependente do poder central. Destaca ainda o jurista:

A teorização da divisão tripartida dos poderes, em Executivo, Legislativo e Judiciário, é moderna, está em MONTESQUIEU. Mas sua prática remota à antiguidade Greco-romana. Em Roma, era nítida a preocupação de distinguir as funções do governo e de confiá-las a órgãos diferentes. (TABOSA, 1999, p.107) 
Não há dúvidas de que o estado feudal foi um período de estagnação cultural e política, como diz Azambuja (2005, p.143): “Os primeiros séculos da era medieval foram impróprios para a elaboração de qualquer conceito de estado". Segundo o autor, trata-se de um período em que houve vasta fragmentação, uma vez que cada feudo apresentava regramentos próprios e as esferas de poder concentravam-se no interior de cada feudo. Deve-se ressaltar que foi um período de grande instabilidade política.

Superado o estado feudal, entra em cena o estado absolutista, no qual houve um predomínio da realeza. É importante destacar, notadamente por dentro do objeto do nosso estudo, que em tal período houve uma profunda centralização política, encontrava-se nas mãos do soberano as funções de legislar, julgar e executar as leis e administrar o estado. Diante da inviabilidade de conflitos políticos, uma vez que o poder estava centralizado em única pessoa, houve uma profunda estabilidade política.

Com o advento das ideias iluministas, sobreveio o estado liberal, marcado por uma redefinição daquilo que se entendia por estado. Dentro deste cenário, teóricos como John Locke publicam o primeiro ensaio daquilo que seria a teoria da tripartição dos poderes. Em sua obra ele distingue as funções legislativa, executiva e federativa. Posteriormente, utilizando-se das sementes lançadas por Locke, o Barão de Montesquieu redige a moderna teoria da tripartição dos poderes. Nas palavras de Liberato (2010, p. 5,):

Eis aqui um ponto crucial das leituras que são feitas sobre Montesquieu, uma vez que, como homem de seu tempo, não se podia exigir que antecipasse - em um estado absolutista como a França do século XVIII - a dinâmica política da interação das funções estatais nos séculos vindouros. Contudo, o que era avanço no século XVIII, passou a retrocesso no século XX. Se 0 juiz nulo politicamente e desprovido de anima (de vontade própria) era 'garantia de justiça' na transição do Estado absolutista para o Estado liberal, pela aplicação linear da lei posta, nos séculos seguintes (e especialmente a partir da segunda metade do século $X X$ ) essa ideologia foi posta a duras provas, conducentes a uma reflexão sobre o papel dos juízes e, particularmente, das Cortes Constitucionais, já agora sem os arroubos de fins do século XIX e início do século XX, marcados que foram pela Escola do Direito Livre e o temos da 'ditadura dos juízes'.

Segundo Souza (2010), a tripartição dos poderes descrita por Montesquieu, vislumbra a ideia de três funções pacíficas e harmônicas, de forma que cada esfera exerce as suas atribuições sem que haja uma interferência de atuação de um sobre o outro. Destaca-se ainda das palavras da autora, retratando as ideias de Montesquieu, a instabilidade da função jurisdicional diante das demais funções, uma vez que este devia se mostrar neutro diante do contexto político da época.

Sabe-se que o fenômeno da globalização tem sido responsável por acarretar inúmeras transformações sociais, gerando, a cada dia, novas demandas, e questionamentos, a atuação do legislativo passa a ser cada vez mais necessária e ágil, de forma que haja uma harmonia entre os fatos sociais e as regras de condutas previstas para a sociedade.

Porém é sabido que a atuação do legislativo tem sido deficiente, atua-se em passos lentos, as novas demandas e anseios sociais ficam sem respostas. As sim, com o escopo de verem tutelados seus direitos, a sociedade busca o amparo do judiciário, solicitando respostas. Sustenta Capelleti (1999, p. 43): “Certamente, o declínio da confiança nos parlamentares constitui fenômeno que se apresenta com diversos sentidos e gravidade em muitos países; em certa medida, porém, constitui elemento característico de todo o mundo ocidental".

Portinaro (2006) elenca situações que justificam uma maior atuação por parte do judiciário na política. Dentre as estudadas pelo teórico, merece destaque a tendência da função legislativa e executiva de delegar questões para a apreciação do judiciário, a ampliação do acesso à justiça, possibilidade do controle de constitucionalidade das normas. 
Assim, observa-se que a teoria dos três poderes ocupa-se, principalmente, com o estudo do funcionamento das instituições políticas. Assim, o escopo de abordar-se a separação dos poderes é chegar ao tema da judicialização da política, uma vez que este guarda estreita ligação com o acima mencionado.

\section{JUDICIALIZAÇ̃̃O DA POLÍTICA}

Segundo Peixinho (2008), a judicialização da política tem por significado a intervenção decisória do Poder Judiciário com capacidade de afetar a conjuntura política nas democracias contemporâneas. A consequência imediata dessa intervenção é a ampliação do poder judicial em matérias que seriam reservadas às competências dos Poderes Executivo e Legislativo com inspiração na teoria do checks and balances.

Em decorrência de mudanças sociais, políticas e econômicas, ocorridas na sociedade, no atual contexto social, conforme abaixo será delineado, o judiciário adquire novas funções e passa a exerceu um novo papel, notadamente pela postura interpretativa manifestada em recentes julgados. É esse fenômeno que se denomina judicialização da política. Nas palavras de Capelleti (1999, p. 49, destaques originais):

\begin{abstract}
[...] assitir-se-á então ao emergir do judiciário como um 'terceiro gigante' na coreografia do estado moderno. Os tribunais judiciários ordinários - 0 'ramo menos perigoso', segundo a célebre definição de Alexandre Hamilton - passaram com audácia a aceitar a tarefa de ultrapassar o papel tradicional de decidir conflitos de natureza essencialmente privada. Todos os juízes, e não apenas alguns daqueles novos juízes especiais (ou 'quase-judiciais'), tornaram-se, dessa maneira, os controladores não só da atividade (civil e penal) dos cidadãos, como também dos 'poderes políticos', nada obstante o enorme crescimento destes no estado moderno, e talvez justamente em virtude desse crescimento.
\end{abstract}

Os séculos XVIII até XX são marcados por profundas alterações sociais, econômicas e políticas. Diante de tal contexto, o judiciário adquire novas funções, além das tradicionalmente exercidas. As mudanças colocariam, sob a égide do judiciário, contendas antes não suscitadas, de forma que este adquiriu uma atuação positiva. Gradativamente, suplantou-se a ideia de um judiciário inerte, mero aplicador da Lei.

Tendo em vista a aquisição de uma postura ativa por parte do judiciário brasileiro, o qual se torna uma figura central no papel da judicialização da política. Nas palavras de Schmidt Nero (2011, p. 89):

\begin{abstract}
Entretanto, se é certo que a judicialização da política se vem afirmando, entre nós, de modo contrário a processos clássicos como o americano - no qual ela deriva da vontade dos próprios fundadores das instituições republicanas - o italiano e o francês, em que a iniciativa do judiciário em limitar o poder político foi determinante, não deixa também de ser verdadeiro que tal resistência vem perdendo força. Em razão disso, a presente pesquisa sustenta que a iniciativa dos intérpretes da Constituição, constante no recurso às Adins, estaria induzindo uma atitude mais favorável por parte do STF no que se refere à assunção de novos papeis. O Tribunal começa a migrar, silenciosamente, de uma posição coadjuvante na produção legislativa do poder soberano, de acordo com os cânones clássicos do republicanismo jacobino, para uma de ativo guardião da Carta Constitucional e dos direitos fundamentais da pessoa humana.
\end{abstract}

Sobre as causas responsáveis por tal fenômeno, destaca-se o estudo de Capelletti (1999, p. 73-74), o qual buscou responder, na obra Juízes Legisladores, se o magistrado exerce papel de mero aplicador do direito ou se a atividade transcende a mera literalidade.

Efetivamente, eles são chamados a interpretar, por isso, inevitavelmente a esclarecer, integrar, plasmar e transformar, e não raro a criar o 'ex novo' direito. Isso não significa, ora, que sejam legisladores. Existe realmente, como me proponho agora a demonstrar, essencial diferença entre processos legislativo e judicial. 
Conforme salientado, no exercício da atividade interpretativa, cria-se, por vezes, novo direito. Em tais casos, complementando o que já foi destacado nas linhas anteriores, os julgadores são convidados a interpretar matérias não apreciadas pela função legislativa, e, aqui, tem-se claramente a criação do direito asseverada nas palavras do autor.

Destaca-se como um dos fatores responsáveis por tal fenômeno, o fato de o legislativo não acompanhar, no que concerne a criação de normas, a velocidade dos fatos sociais. Dessa forma, a sociedade modifica-se a passos rápidos, enquanto a produção normativa caminha em baixa velocidade.

Tendo em vista que com o surgimento de fatos sociais, surgem novas questões e novos conflitos de interesses, não há como a sociedade esperar por uma atuação legislativa para obter resposta para os anseios. Assim, independentemente da existência de norma sobre o caso concreto, busca na seara do Poder Judiciário, a resolução de lides.

É notadamente no exercício da função jurisdicional nestes casos que se tem uma interpretação criadora, pois não se trata de aplicar o direito ao caso concreto. Neste caso, o direito não existe, o teor da decisão criará o direito. É o fenômeno da politização da justiça, a qual passa a exercer a função típica do legislativo.

Segundo Schattschneider (1960 apud TAYLOR, 2007, p. 229, destaque original):

\section{JUDICIALIZACÃ̃O DA POĹTICA EXTERNA}

Em meados de 2005, o juiz federal brasileiro Julier Sebas Tião da Silva, por meio de ato judicial, determina a fiscalização de cidadãos estadunienses que entrassem no território brasileiro. 0 decisum utilizou como fundamento a aplicação do princípio da reciprocidade, basilar em todas as relações internacionais,
O Poder Judiciário possui um impacto significativo na elaboração das políticas públicas: os tribunais influenciam o que Schattschneider (1960) chamava de 'definição das alternativas' pelo sistema político. [...] Cada vez mais, a visão clássica dos tribunais como instância estritamente legais tem sido contatada pelas crescentes evidências de seu papel político e de seu impacto diário nas políticas públicas.

Convém, ainda, destacar, Taylor (2007, p. 248, destaque original):

É amplamente reconhecido que, embora o Judiciário não possua "nem a bolsa nem a espada" - ou seja, nem os poderes orçamentários do legislativo nem os poderes coercitivos do executivo-, ele tem um considerável poder político como depositário da fé pública nas regras do jogo. 0 judiciário desempenha um papel central na determinação e aplicação de princípios tanto constitucionais, quanto ideais, tais como Rechstaat ou état de droit.

Partindo-se de uma visão tradicional do papel do judiciário, segundo a qual a função precípua do órgão é a de simples aplicador da lei, a intervenção na resolução de conflitos, deveria restringir-se a de mero interpretador das normas, aplicando o direito ao caso concreto.

Destaca-se que no tocante as relações externas, tem-se observado uma atuação ativista, fornecendo resposta para questões não apreciadas pelo legislativo. E, é em tais casos, que percebe-se uma postura de politização do judiciário. É esse tema, analisando as suas consequências, que passaremos a discorrer.

que tem por escopo propiciar o equilíbrio e a equivalência. Diante de um contexto, no qual se aplicava a brasileiros, severas medidas de identificação, quando da entrada em solo norte-americano, invocando a manutenção da equidade, o douto magistrado determinou que assim fosse feito em território nacional. 
Esse é apenas um exemplo de atuação do Poder Judiciário brasileiro que transcende a sua competência, adentrando em matérias que precipuamente pertence à outra função.

Dispões o Art. 84, VII da atual Carta Magna, que compete ao presidente da República, "manter relação com estados estrangeiros". A breve leitura da síntese sobre a temática, acima apresentada, demonstra que houve uma atuação por parte do judiciário sobre um tema definido como atribuição do executivo.

Para melhor compreensão do tema, faz-se necessário colacionar o conceito de relações internacionais:

As Relações Internacionais (abreviadas como RI ou REL) visam ao estudo sistemático das relações políticas, econômicas e sociais entre diferentes países cujos reflexos transcendam as fronteiras de um Estado, as empresas, tenham como locus o sistema internacional. Entre os atores internacionais, destacam-se os Estados, as empresas transnacionais, as organizações internacionais e as organizações não-governamentais. Pode se focar tanto na política externa de determinado Estado, quanto no conjunto estrutural das interações entre os atores internacionais (DICIONÁRIO ELETRÔNICO WIKIPÉDIA, 2012, ONLINE).

Assim, observa-se que as relações internacionais são aquelas que transcendem as fronteiras do estado, de forma que os reflexos para o país podem repercutir em vários fatores sociais e econômicos. Com o escopo de proteger as repercussões, outorgou-se ao chefe de Estado a atribuição de comandar tais ações.

Retomando a discussão sobre a decisão judicial, relata-se que foram comuns comentários sociais informando que teria havido uma usurpação de competência, pois se trata de atribuição discricionária do executivo, de forma que a este compete decidir sobre como atuar, qual é o devido momento de fazer, e a melhor forma. É sabido que o presidente da República assume a função de chefe de Estado, logo, é deste o dever constitucional de gerir as relações externas.
É sabido que as decisões jurisdicionais possuem uma estrutura própria, deve o juiz apreciar o caso de acordo com o seu livre convencimento, ou seja, verificar os elementos colacionados aos fólios para decidir o conflito. Requer-se do órgão julgador apenas que motive a decisão, explane para as partes e para a sociedade quais foram os elementos que fundamentaram o seu convencimento.

Nas palavras de Montenegro (2005, p. 64):

Exige-se do magistrado, em casos tais, que aponte de forma direta quais os argumentos trazidos pelo autor, que the convenceram do preenchimento dos requisitos específicos, apoiando a sua decisão em fatos do processo, além dos documentos vindos com a petição inicial. A decisão que assim não se apresenta é nula de pleno jure, por afrontar o princípio constitucional estampado no aer. 93, inciso IX, do Texto Maior, assegurador da transparência das decisões judiciais, arrepiando, em ato contínuo, o princípio do devido processo legal, tudo o que pode e deve ser reconhecido de ofício pelo tribunal, por se apresentar como matéria de ordem pública, não é de mero interesse particular das partes em litígio.

Logo, facilmente se percebe que o teor das decisões judiciais tem uma lógica própria, uma estrutura peculiar, qual seja o livre convencimento do magistrado. No tocante às relações externas, a maneira como tais relações ocorrem, obedece a uma estrutura peculiar, que tem por escopo propiciar a maior efetividade das relações entre estados, e garantir que determinadas metas sejam atingidas. Então, indaga-se até que ponto a intervenção do judiciário, por meio das suas decisões, pode beneficiar ou prejudicar as relações do Brasil com outros estados.

Sobre o tema, convém destacar as palavras de Souza (2010), na sua monografia de pós-graduação intitulada: "A judicialização da política externa brasileira: a disputa na OMC sobre os pneus reformados e a Arguição de Descumprimento de Preceito Fundamental no STF":

[...] A análise de temas de política externa por parte dos Tribunais é objeto de polêmica. Se por um lado, 
o Poder Judiciário deve aplicar de forma plena a sua jurisdição, exercendo seu controle de legalidade sobre todos os domínios da política. Por outro, alega-se que o Judiciário não teria ferramentas judiciais idôneas para resolver controvérsias vinculadas a questões de política externa. Esses assuntos seriam, por natureza, de discricionariedade exclusiva do Poder Executivo e Legislativo, não podendo o judiciário adentrar em seu mérito (SOUZA, 2010, p. 24).

Assim, deve-se avaliar as benesses e consequências de uma atuação do judiciário que afeta a política externa. É inegável que, apesar das repercussões, não há como se pensar em deixar de responder a um jurisdicionado por se tratar de matéria não legislada, ou por se pensar que a atuação terá repercussão na política externa.

De início, invoca-se a aplicação do Princípio da Inafastabilidade do Poder Judiciário, sobre o qual transcrevo o conceito da jurista Grinover (2007, p. 13, destaque original):

O princípio da inafastabilidade do controle jurisdicional foi assim se afirmando em todos os Estados modernos, indicando ao mesmo tempo o monopólio estatal na distribuição da justiça (ex parte principis) e o amplo acesso de todos à referida justiça (ex parte populi). A Constituição brasileira de 1946 consagrou o princípio, que hoje vem expresso pelo art. $5^{\circ}$, inc. XXXV da CF: 'A lei não excluirá da apreciação do Poder Judiciário lesão ou ameaça a direito'. Mas o acesso aos tribunais não se esgota com o poder de movimentar a jurisdição (direito de ação, com o correspondente direito de defesa), significando também que o processo deve se desenvolver de uma determinada maneira que assegure às partes o direito a uma solução justa de seus conflitos, que só pode ser obtida por sua plena participação, implicando o di- reito de sustentarem suas razões, de produzirem suas provas, de influírem sobre o convencimento do juiz. Corolário do princípio da inafastabilidade do controle jurisdicional são todas as garantias do devido processo legal, que a Constituição brasileira detalha a partir do inc. LIV do art. $5^{\circ}$, realçando-se, dentre elas, o contraditório e a ampla defesa (inc. LV do mesmo artigo).

Desse modo, verifica-se que não há como uma questão deixar de ser tutelada pela ausência de atuação do legislativo ou pelas repercussões que esta pode ocasionar na seara externa. Conforme descrito nas linhas anteriores, que a inércia da função legiferante aumenta a atuação da função judicante. Então, constata-se que não há como o judiciário se eximir de responder as demandas.

De outra banda, algumas demandas, a exemplo da citada na abertura deste tópico, repercutem nas relações externas, representando uma atuação da função jurisdicional na esfera, que a princípio deveria ser competência do poder executivo, atribuição precípua do chefe de Estado, conforme preceito da Carta Magna. Então, indaga-se, diante de tal conflito, qual seria a adequada solução. Ou se faz a opção por deixar o jurisdicionado sem resposta ou atende-se a demanda, fornecendo à parte uma resposta, a qual é elaborada sob a ótica interna das decisões do judiciário, independente da repercussão nas relações externas que esta pode ocasionar.

Assim, compreende-se que o fenômeno da judicialização da política é real, e presente na atual conjuntura social. Fato este que nos leva a uma série de benesses e também possíveis consequências.

\section{CONCLUSÃO}

É sabido que o Poder Judiciário tem exercido cada vez mais um papel ativo no contexto social, trata-se de uma atuação que transcende a mera aplicabilidade da literalidade da lei. Tem-se vivido o fenômeno denominado judicialização da política, o qual é marcado, em suma, por um papel político dos juízes, principalmente em virtude da expansão do poder dos tribunais. Trata-se de decisões que afetam, de alguma forma, a conjuntura política, econômica e social. 
Atribui-se como uma das causas capaz de justificar o fenômeno a debilidade do poder legislativo, o qual não tem se mostrado hábil para criar normas de condutas para todos os fatos sociais ocorridos no cotidiano. Destaca-se, ainda, o fenômeno da globalização, o qual é responsável por transformar diariamente a sociedade, criando novas situações, seja em virtude de proporcionar ao ser humano contato com novas tecnologias, com diferentes pessoas ou até mesmo por compartilhar diversas informações. Assim, observa-se um mundo em constante transformação.

Diante desta realidade, contata-se que a função legiferante não tem se mostrado hábil o suficiente para atender a todas estas demandas. Assim, criam-se novas situações que precisam de resposta. Logo, o indivíduo, ante a ausência de uma regra específica de conduta, busca no judiciário uma resposta para o entrave.

Tendo em vista o Princípio Constitucional da Inafastabilidade do Poder Judiciário, conclui-se que não há como o judiciário deixar de responder a uma demanda do jurisdicionado, ainda que o tema não tenha sido objeto de análise por parte da função legiferante.

Ocorre que algumas decisões transcendem o conteúdo inter partes (entre as partes) e adquirem repercussão internacional, de forma que passa a afetar as relações externas. Porém há de ser destacado que assuntos relativos a questões entre estados pertencem à atribuição do poder executivo, notadamente a figura do presidente da República, consoante preceito constitucional.

\section{REFERÊNCIAS}

ARISTÓTELES. Política. 3. ed. Brasília: UnB, 1997.

AZAMBUJA, Darcy. Teoria geral do Estado. São Paulo: Globo, 2005.

BONAVIDES, Paulo. Ciência política. 10. ed. São Paulo: Malheiros, 2000.
Assim, tem-se um conflito, posto que invoca-se o Princípio da Inafastabilidade do Poder Judiciário, porém, de outra banda, observa-se uma usurpação de função, a interferência "indevida" de um poder sobre o outro.

Diante da tal realidade, questiona-se a aplicação da Teoria da Tripartição dos Poderes, segundo a qual existem três funções indivisíveis, cada uma com atribuições, previamente estabelecidas. Aceitando-se como válida a ocorrência da usurpação de funções, questiona-se a aplicabilidade e validade das premissas apresentadas por esta teoria.

Fixados os parâmetros delineadores do fenômeno da judicialização da política, voltou-se a atenção para a repercussão nas relações externas. Aqui, trata-se de fator relevante em virtude da repercussão que uma decisão judicial pode causar nas relações internacionais.

Questiona-se a possibilidade de usurpação de função do poder executivo, assim, entende-se que se trata de uma função judiciária que além de atuar criando o direito, ante a ausência de norma para o caso, por vezes, invade a atribuição concedida ao chefe de Estado pela Carta Magna.

Diante da extensão deste trabalho, bem como por apego a uma rigorosa delimitação do tema, não se propõe atingir uma conclusão precisa sobre o tema, mas propor à comunidade acadêmica elementos e posicionamentos para se analisar e criticar o problema posto em questão.

BRASIL. Constituição (1988). Constituição da República Federativa do Brasil. Brasília: Senado Federal, 1988.

CAPPELLETTI, Mauro. Juízes legisladores. Trad. Carlos Alberto Álvaro de Oliveira. Porto Alegre: Fabris, 1999. 
COULAGENS, Fustel de. A Cidade Antiga: estudo sobre o culto, o direito e as instituições da Grécia e de Roma. São Paulo: Martin Claret, 2006.

DICIONÁRIO Eletrônico Wikipédia. Relações internacionais. Wikipédia [2012, online]. Disponível em: <http://pt.wikipedia.org/wiki/Rela\%C3\%A7\%C3\% B5es_internacionais>. Acesso em: 28 maio 2012.

FINLEY, Moses I. Democracia antiga e moderna. Rio de Janeiro: Graal, 1988.

GRINOVER, Ada Pellegrini. A inafastabilidade do controle jurisdicional e uma nova modalidade de autotutela. Parágrafos únicos dos artigos 249 e 251 do Código Civil. Revista Brasileira de Direito Constitucional - RBDC, n. 10, p13-119, jul./dez. 2007.

HAMON, Francis; TROPER, Michel; BURDEAU, Georges. Direito Constitucional. 27. Ed. Barueri: Manole, 2005.

LIBERATO, Gustavo Tavares Cavalcanti. Sistema de freios e contrapesos, judicialização da política e o Supremo Tribunal Federal: uma tese para a atual postura do STF. Revista Científica da Associação Cearense do Ministério Público - ACMP, Fortaleza, v. I, nº 1, p. 36-49, jun/ 2010.

Montenegro FILHo, Misael. Curso de Direito Processual Civil, volume 01: teoria geral do processo e processo de conhecimento. São Paulo: Atlas, 2005.

MONTESQUIEU, Charles de Secondat, Baron de. 0 Espírito das Leis. 2. ed. São Paulo: Martins Fontes, 1996.

PÁDUA, Marsílio de. 0 Defensor da paz. Rio de Janeiro: Vozes, 1995.
PEIXINHO, Manoel Messias. O princípio da separação dos poderes, a judicialização da política e direitos fundamentais. Anais do XVII Congresso Nacional do CONPEDI, realizado em Brasília - DF, nov/2008. Disponível em: <http://www.conpedi.org.br/manaus/ arquivos/ anais/brasilia/07_252.pdf >. Acesso em: 25 maio 2012.

PORTINARO, Pier Paolo. Tirania doa juízes ou anarquia dos advogados? In: COSTA, Pietro; Zolo, Danilo (orgs). 0 estado de direito: história, teoria, crpitica. São Paulo: Martins Fontes, 2006.

SCHMIDT NETO, André Perin. A Judicialização da política e das relações sociais no Brasil. Revista da Faculdade de Direito - UniRitter, Porto Alegra, v. 1, $\mathrm{n}^{0}$. 10, p. 83-96, 2009.

SOUZA, Danielle. A judicialização da política externa brasileira: a disputa na OMC sobre os pneus reformados e a Arguição de Descumprimento de Preceito Fundamental no STF. Monografia (2010), 86f. Pós-graduação em Direito pelo Instituto Internacional de Brasília. DF. Disponível em: <ttp://repositorio.bce.unb.br/ bitstream/10482/5913/1/2010_Danielle Aleixo ReisdoValleSouza.pdf>. Acesso em: 25 de maio de 2012.

TABOSA, Agerson. Direito Romano. Fortaleza: Imprensa Universitária/UFC, 1999.

TAYLOR, Matthew M. O Judiciário e as políticas públicas no Brasil. Revista de Ciências Sociais, Rio de Janeiro, v. 50, no. 2, p. 229-257, 2007. 